\title{
Polish Gynecological Society recommendations for labor induction
}

\author{
Board of Experts: \\ Dorota Bomba-Opoń ${ }^{1}$, Krzysztof Drews ${ }^{2}$, Huber Huras ${ }^{3}$, Piotr Laudański ${ }^{4}$, \\ Tomasz Paszkowski ${ }^{5}$, Mirosław Wielgoś ${ }^{1,6}$ \\ ${ }^{1} 1^{\text {st }}$ Chair and Department of Obstetrics and Gynecology, Medical University of Warsaw, Poland \\ ${ }^{2}$ Chair of Perinatology and Gynecology, Departament of Perinatology and Women's Diseases, \\ Karol Marcinkowski University of Medical Sciences, Poznan, Poland \\ ${ }^{3}$ Department of Obstetrics and Perinatology Jagiellonian University, Cracow, Poland \\ ${ }^{4}$ Department of Perinatology, Medical University of Bialystok, Poland \\ ${ }^{5} 3^{\text {rd }}$ Chair and Department of Gynecology, Medical University of Lublin, Poland \\ ${ }^{6}$ President of Polish Gynecological Society
}

\section{INTRODUCTION}

Labor induction involves artificial stimulation of childbirth before the natural, spontaneous onset of labor. It is one of the most common procedures in modern obstetrics. The frequency of labor induction has doubled in recent decades due to the development of perinatology and methods of monitoring fetal well-being in particular. Currently, one in five pregnant women and $30-40 \%$ of women delivering vaginally undergo this procedure [1]. Reasons for induction include reduction of the perinatal mortality and morbidity of the fetus and newborn, as well as the reduction of maternal complications. However, as every medical intervention, labor induction is associated with a risk of complications.

\section{QUALIFICATION FOR LABOR INDUCTION}

The risks and benefits associated with labor induction should always be considered in medical management. From the perspective of the child, premature termination of pregnancy may lead to neonatal complications. Conservative treatment, however, increases the risk of intrauterine hypoxia caused by placental insufficiency or intrauterine infection in cases of cervical dilation or premature rupture of membranes. On the one hand, induction of labor reduces a threat to life and health of the mother, for example, in pregnancies complicated by preeclampsia; on the other hand, it increases the risk of prolonged labor, uterine atony, obstetric hemorrhage and cesarean section. When qualifying a pregnant woman for induction of labor, one should always take account of gestational age based on ultrasound examination performed in the first trimester, the severity of the irregularities observed, parity, the maturity of the cervix and the presence of any contraindications (Tab. 1).

The history of the disease should include a document qualifying for labor induction based on clinical data. Before the planned induction, the pregnant woman must give informed consent.

\section{Recommendation \\ The decision to induce labor should always be justified on medical grounds and preceded by obtaining a written informed consent from the pregnant woman.}

\section{Table 1. Contraindications to labor induction}

\begin{tabular}{l} 
Contraindications to labor induction \\
\hline Placenta or vasa previa \\
Surgical procedures on the uterine body (e.g. classical \\
cesarean section, enucleation of uterine fibroids) \\
\hline Intrapartum uterine rupture \\
\hline Invasive cancer of the cervix \\
\hline Active genital herpes infection \\
Abnormal fetal position (transverse, breech) \\
\hline Other contraindications to vaginal delivery
\end{tabular}




\section{INDICATIONS FOR LABOR INDUCTION}

\section{A post-term pregnancy}

A post-term pregnancy is defined as a pregnancy that lasts more than 42 weeks ( 294 days or more from the first day of the last menstrual period). The International Statistical Classification of Diseases and Related Health Problems (ICD-10) from 2015 uses the term 'a prolonged pregnancy', which covers a post-term pregnancy. A post-term fetus is defined as a fetus in gestation lasting full 42 weeks or more (294 days or more from the first day of the last menstrual period). A full-term pregnancy is defined as a pregnancy at 37 weeks to 40 weeks +6 days, whereas a late-term pregnancy is a pregnancy at 41 weeks to 41 weeks +6 days. Diagnosing a pregnancy that lasts 42 weeks or longer involves estimating the date of delivery based on the date of the last menstrual period or ultrasound examination. If the date of delivery is estimated on the basis of ultrasound examination in the first trimester, the incidence of post-term pregnancies is approximately $2 \%$ and labor is induced less often than in pregnancies in which the date of delivery is determined by the date of the last menstrual period [2,3]. Previous post-term pregnancy increases the risk of recurrence in subsequent pregnancies. The risk of anther post-term pregnancy is two- to fourfold higher, and even higher in the case of two consecutive post-term pregnancies in the past [4]. Meta-analyses of randomized trials indicate that labor induction in uncomplicated post-term pregnancies is associated with a reduced risk of intrauterine fetal death and a lower rate of caesarean sections, compared to expectant management. It has also been found that labor induction in post-term pregnancies is associated with reduced perinatal morbidity and in particular a lower risk of meconium aspiration [1,5]. Labor induction is therefore justified in well-dated, single, uncomplicated pregnancies between 41 weeks and 41 weeks +6 days regardless of the state of the cervix. If a woman decides not to have her labor induced further care and monitoring should be carried out in a hospital [6]. Increased prenatal control should include ultrasound evaluation of amniotic fluid volume and at least one cardiotocographic record per day [7]. Induction of labor should be discussed again with a pregnant woman diagnosed with oligohydramnios and/or irregularities in the cardiotocographic records indicative of a threat to fetal well-being.

\section{Recommendation}

Labor induction is recommended in well-dated pregnancies (taking account of fetal biometry between 8 and 14 weeks of gestation) at 41 weeks to 41 weeks +6 days, regardless of the state of the cervix, taking account of the fact that interventions at this time reduce perinatal mortality without increasing perinatal morbidity or the percentage of caesarean sections.

\section{Pre-term pre-labor rupture of membranes before 37 weeks of gestation}

Pre-term pre-labor rupture of membranes (PPROM) before 37 weeks of gestation occurs in $3 \%$ of pregnancies and is the cause of $1 / 3$ of pre-term deliveries. The fetus/infant is exposed to a higher risk of morbidity and mortality associated with PPROM than the mother. The management of women with PPROM must take account of a number of factors, including gestational age, the availability of the intensive care unit, the presence of infection in the mother/fetus, the onset of uterus contraction, placental abruption, the position of the fetus, the fetal heart rate and prediction of fetal lung maturity, and the maturity of the cervix. Labor induction in women with PPROM is clinically justified in cases of intrauterine infection, when fetal health may deteriorate as a result of expectant management and there are no available therapeutic methods other than delivery.

The results of randomized trials comparing direct labor induction and expectant management do not indicate significant differences in the incidence of maternal-fetal complications before 37 weeks of pregnancy in the absence of symptoms of infection in the mother and intrauterine fetal asphyxia [8-10]. A 48-hour antenatal corticosteroid therapy is recommended before 34 weeks of gestation in order to reduce the risk of neonatal complications [11]. It is not recommended to repeat corticosteroid therapy if delivery does not occur within seven days, during the period of their optimum action [12].The results of randomized trials suggest that the use of prophylactic antibiotics in PPROM before the onset of contractions before 37 weeks of gestation can reduce the risk of intrauterine infection and lengthen the pregnancy. The combination of amoxicillin and clavulanic acid should be avoided in prophylactic therapy due to an increased risk of necrotising enterocolitis in prematurely born infants [13].

\section{Recommendations}

1. Labor induction is not recommended in pregnant women with PPROM before 34 weeks of gestation in the absence of symptoms of intrauterine infection due to a high risk of complications associated with pre-term birth. Expectant management using a steroid therapy and antibiotic prophylaxis is recommended.

2. Labor induction is not recommended in pregnant women with PPROM between 34 and 37 weeks of gestation in the absence of symptoms of intrauterine infection because 
it does not reduce the risk of complications of neonatal sepsis and may be associated with a higher risk of respiratory complications in newborns. Expectant management with prophylactic antibiotics is recommended.

3. The labor in women with PPROM is recommended in cases of intrauterine infection, regardless the gestational age. Labor approach need to be adequate to clinical conditions.

\section{PPROM after 37 weeks of gestation}

PPROM before the onset of contractions occurs in $8 \%$ of full-term pregnancies [14]. In expectant management, spontaneous uterine contractions occur within 72 hours in 95\% of women with PPROM [14]. Active management aimed at the induction of uterine contractions through the administration of oxytocin or prostaglandins reduces the risk of inflammatory complications in the mother without increasing the incidence of operative delivery [15]. The results of randomized trials also indicate that antibiotic therapy and hospitalization in intermediate and intensive care units are less likely after labor induction [15]. The use of antibiotics is recommended in pregnant in women with positive or unknown group B streptococcus (GBS) colonization [16]

\section{Recommendation}

Labor induction is recommended in pregnant women with PPROM after 37 weeks of gestation due to a reduced risk of maternal and neonatal complications.

\section{Suspected large-for-gestational-age fetuses}

Each fetus with a weight above the 90th percentile for the gestational age can be considered large for gestational age (LGA). Estimated weight amounting to 4,500 grams is generally treated as the threshold value in the diagnosis of macrosomia. Macrosomia is an important indication for an operative delivery and may be the cause of adverse perinatal outcome and in particular traumatic injuries to mothers and infants $[17,18]$. Macrosomia may be related to constitutional factors (e.g. family history, male sex, ethnicity), environmental factors (diabetes in the mother, weight gain in the mother, maternal obesity, post-term pregnancy) or genetic disorders (Pallister-Killian syndrome, Beckwith-Wiedemann syndrome, etc.) $[19,20]$. Two-dimensional ultrasound is commonly used to diagnose macrosomia and LGA. The Hadlock formula (including biparietal diameter [BPD], abdominal circumference $[A C]$ and femur length $[F L]$ ) has the highest predictive value in a population of people without diabetes [21]; $A C>35 \mathrm{~cm}$ have predictive values for macrosomia, but no test is sufficiently sensitive and specific [22]. It should be noted that all methods currently used to estimate the size of a fetus, especially of a large fetus, have little predictive value. The margin of error may reach $15-20 \%$, especially in suspected macrosomia and advanced delivery. Therefore, there is no conclusive evidence that labor induction can reduce the morbidity of mothers and newborns in pregnancies with suspected fetal macrosomia. The results of randomized trials conducted in 19 centers in France, Switzerland and Belgium have demonstrated that labor induction between 37 and 39 weeks of pregnancies with LGA fetuses diagnosed by ultrasound (above the 90th percentile for the gestational age) reduces the risk of shoulder dystocia and the related neonatal morbidity compared with expectant management [23]. However, the number needed to prevent one neonatal clavicular fracture during labor induction was 60 [24]. There were no significant differences in the percentage of caesarean sections, but early induction of labor improved the chance for vaginal delivery. Unfortunately, there were more cases of vaginal cracking and damage to the anal sphincter in the group of women who had their labor induced. The neonatal complications included a higher incidence of hyperbilirubinemia and the need for phototherapy in neonates after labor induction, especially before 38 weeks of gestation.

Due to the increased risk of neonatal complications, especially if caesarean section must be performed due to inefficient induction, labor must not be induced in pregnancies with suspected LGA fetuses before 39 weeks.

Induction of labor in pregnancies with suspected LGA fetuses decreases the need for caesarean section and difficult operative delivery [24]. However, the exact size of the fetus must be estimated for the procedure to be efficient and burdened with the least risk of complications. If the ultrasound estimated fetal weight is above $4.500 \mathrm{~g}$, labor induction should not be performed due to a high risk of shoulder dystocia [25].

\section{Recommendations}

1. Labor induction in pregnancies with suspected LGA fetuses can be considered after 39 weeks, as it may reduce the risk of shoulder dystocia and caesarean section, but a relatively high risk of error in the ultrasound estimation of the fetal weight must be taken into account.

2. Labor induction at the estimated fetal weight $>4.500 \mathrm{~g}$ is not recommended due to a high risk of shoulder dystocia.

\section{Suspected intrauterine growth restriction (IUGR)}

IUGR generally refers to an estimated fetal weight of less than the $10^{\text {th }}$ percentile for the gestational age. It should be noted that this group of fetuses includes both healthy, 
constitutionally small newborns whose body weight and length are genetically conditioned (small for gestational age - SGA) and the fetuses that have failed to achieve their growth potential due to pathology and are classified as having IUGR. In contrast to the IUGR group, there is no increased risk of intrauterine death or hemodynamic abnormalities in the SGA group of fetuses. About $10 \%$ of perinatal mortality is due to IUGR. The risk of perinatal death in a child with a birth weight of $<10^{\text {th }}$ percentile is twice as high as in an infant with a normal birth weight [26, 27]. Obstetric management in suspected fetal growth disorders involves estimating gestational age based on the crown rump length $(C R L)$ measured in the first trimester of pregnancy or the transverse cerebellar diameter measured in the second trimester (if the CRL is unavailable). Serial ultrasound measurements carried out at intervals of two weeks should determine the potential growth of the fetus and assess the vascular flow. If irregularities are confirmed and IUGR is diagnosed, the patient should be directed to a tertiary referral center. Depending on the severity of hemodynamic changes and the week of gestation, the well-being of the fetus should be monitored through Doppler assessment of the umbilical artery, the middle cerebral artery, ductus venosus and cardiotocography (CTG) for early diagnosis of fetal decompensation $[27,28]$.

Due to the lack of methods of treatment and prevention of IUGR, the labor is the only effective way to affect the course of this disease. Labor should be considered if the risk of death or harm to the fetus resulting from remaining in utero is higher than the risk of complications resulting from pre-term birth. The decision on the optimum date of the labor should be made by an obstetric and neonatal council and discussed with a patient.

According to research results, SGA fetus without concomitant pathology should be delivered at term. SGA itself is not an indication for induction of labor. In IUGR pregnancies without sights of fetal decompensation, delivery can be postponed to 37 weeks [28].

It should be taken into account that intrauterine growth restriction developing after 34 weeks of gestation is not always associated with abnormal umbilical blood flow; hemodynamic changes may be slightly increased and relate mainly to a reduced pulsatility index in the middle cerebral artery [26].

\section{Recommendations}

1. Labor induction in women with IUGR is not recommended before 34 weeks of gestation due to a high risk of complications associated with pre-term delivery.

2. Labor induction in women with IUGR is not recommended between 34 and 36 weeks due to a risk of complications associated with late pre-term delivery.

3. Labor induction in women with suspected IUGR is recommended after 37 weeks due to an increased risk of intrauterine fetal death.

\section{A twin pregnancy}

A twin pregnancy is associated with a higher risk of obstetric failures, including intrauterine death of one or both fetuses, compared to a single pregnancy. A cohort analysis indicates that the risk of perinatal mortality increases in a twin pregnancy after 37 weeks in the same way as after 41 weeks in a single pregnancy [29]. Failures to a large extent are associated with the presence of a single chorion [30]. In monochorionic diamniotic pregnancies, hemodynamic abnormalities related to vascular connections in the placenta are associated with a significantly higher risk of mortality and morbidity of twins compared to dichorionic pregnancies [31]. In monochorionic monoamniotic pregnancies, umbilical cord looping and umbilical cord collision may lead to intrauterine asphyxia during labor [32]. Therefore, a monoamniotic pregnancy is a contraindication to a vaginal delivery.

When choosing the optimum week of delivery, one must, however, take account of the risk of neonatal complications. Data from all twin births that took place in the United States between 2007 and 2010 suggest that neonatal complications occurred less frequently in twins born between 37 and 38 weeks of gestation than in those born between 38 and 39 weeks [33]. Similar results were obtained in the analysis of more than 760 twin births in Canada [34]. The lowest percentage of neonatal complications was noted in cases of births between 36 and 37 weeks in monochorionic pregnancies and between 37 and 38 weeks in dichorionic pregnancies [30]. An Australian study, in which pregnant women with uncomplicated twin pregnancies were randomized for elective birth at 37 weeks of gestation or for expectant management, showed that a lower percentage of complications occurred in cases of early delivery [35].

Twin delivery is one of the biggest challenges of modern obstetrics. Retrospective analyses indicate a higher risk of complications in vaginal deliveries compared to elective caesarean section [36]. This correlation, however, has not been confirmed by the recently published results of a large randomized trial Twin Birth Study. Currently, an uncomplicated diamniotic twin pregnancy with the cephalic presentation of the first twin is not a contraindication to vaginal delivery and labor induction [37].

\section{Recommendations}

1. Labor induction in twin monochorionic diamniotic pregnancy, in the absence of con- 
traindications to vaginal delivery, should be considered between 36 and 37 weeks of gestation due to an increased risk of the intrauterine death of the fetus/fetuses.

2. Labor induction in twin dichorionic pregnancy, in the absence of contraindications to vaginal delivery, should be considered between 37 and 38 weeks of gestation due to an increased risk of the intrauterine death of the fetus/fetuses.

3. Labor induction in twin monoamniotic pregnancy is contraindicated.

\section{A pregnancy complicated by hypertension}

Hypertension occurs in some $10 \%$ of pregnancies and is associated with an increased risk of both maternal and fetal complications. Pre-eclampsia and hemorrhage into the central nervous system are complications associated with the highest mortality rate. Hypertension often leads to iatrogenic pre-term delivery, intrauterine growth retardation and caesarean section. Studies indicate that in the absence of additional complications, delivery between 38 and 39 weeks of gestation compensates for the risk of maternal and neonatal complications [38, 39]. Early delivery should be considered in cases of ineffective antihypertensive therapy or intrauterine growth retardation.

\section{Recommendations}

1. Labor induction in pregnant women with uncomplicated hypertension should be considered after 38 weeks of gestation due to an increased risk of maternal complications.

2. Delivery should be considered in women with hypertension and additional complications, regardless gestational age. Labor approach need to be adequate to clinical conditions.

\section{A pregnancy complicated by diabetes mellitus}

Type 1 and type 2 pregestational diabetes occurs in about $1 \%$ of pregnant women. In recent years, there has been an increase in the incidence of type 2 diabetes in women of childbearing age due to the obesity epidemic. Hyperglycemia and obesity are risk factors for fetal abnormalities, excessive growth of the fetus, hypertension and pre-eclampsia. The severity of diabetic nephropathy and retinopathy may also increase in pregnancy. Hyperglycemia and the resulting fetal hyperinsulinemia affect the severity of metabolic processes and intrauterine fetal growth. The resulting increased demand for oxygen can lead to chronic hypoxia and even death of the fetus in particular at the end of the third trimester of pregnan- cy. Excessive fetal growth is a risk factor for feto-pelvic disproportion and shoulder dystocia. The estimated fetal weight above $4000 \mathrm{~g}$ and/or the difference between abdominal diameter (AD) and biparietal diameter (BPD) above $2.6 \mathrm{~cm}$ have predictive values for shoulder dystocia in diabetic pregnancy [40]. Earlier induction of labor may reduce the risk of complications associated with fetal macrosomia. Unfortunately, fetal hyperinsulinemia inhibits type Il pneumocyte maturation and surfactant production. Infants born to mothers with pregestational diabetes are more likely to have respiratory distress syndrome before 39 weeks of gestation, compared to children of mothers without diabetes. There are no studies evaluating the optimum week of delivery and induction of labor in pregnant women with pregestational diabetes. A randomized trial was conducted over 20 years ago in pregnant women with diabetes treated with insulin, of which only $6 \%$ had pregestational diabetes [41]. Induction of labor at 38 weeks was compared with expectant management and a lower percentage of fetal macrosomia in active management was found.

In the majority of cases, gestational diabetes is diagnosed in the second half of pregnancy in approximately $3.5-5 \%$ of Caucasian women. Growing overweight and obesity among women of childbearing age and changes in the criteria for diagnosing gestational diabetes increase the incidence of gestational diabetes. Just as in pregestational diabetes, the main complications are excessive fetal growth, gestational hypertension, shoulder dystocia and caesarean section. Recent observational and randomized studies have shown that induction of labor in pregnancy complicated by gestational diabetes between 38 and 40 weeks reduces the risk of stillbirth and caesarean section compared to expectant management $[42,43]$. No increased risk of neonatal complications has been found in cases of induction at 39 weeks of gestation.

\section{Recommendations}

1. Labor induction in women with pregestational diabetes mellitus should be considered after 38 weeks due to an increased risk of fetal complications.

2. Labor induction in pregnancy complicated gestational diabetes should be considered after 39 weeks due to an increased risk of fetal complications.

3. In case of suspected excessive fetal growth in diabetic pregnancy when the estimated fetal weight exceeds above $4000 \mathrm{~g}$ and/or the difference between AD and BPD above $2.6 \mathrm{~cm}$, the induction of labor is contradicted due to an increased risk of shoulder dystocia. 


\section{A pregnancy complicated by intrahepatic cholestasis}

Intrahepatic cholestasis of pregnancy (ICP) occurs in approximately $2 \%$ of pregnant women. It usually manifests itself in the third trimester of pregnancy and is associated with severe itching of the skin. The basic criterion for diagnosing ICP is an increased concentration of bile acids. While ICP has a slight impact on the maternal health, it is a significant risk factor for fetal complications including stillbirth. The incidence of intrauterine fetal death increases with the duration of pregnancy and the concentration of bile acids. Observational studies indicate an increased risk after 37 weeks of gestation in cases of severe cholestasis with bile acid concentration greater than $100 \mathrm{mmol} / \mathrm{L}$ [44]. Meconium-stained amniotic fluid also often occurs in pregnancies complicated by cholestasis and bile acid concentration greater than $40 \mathrm{mmol} / \mathrm{L}$, which is often attributed to fetal hypoxia. Unfortunately, there are currently no studies that would make it possible to identify fetuses at risk of intrauterine hypoxia and stillbirth. Therefore, one of the recommended procedures is earlier induction of labor. There are unfortunately no randomized trials allowing for determining the optimum date of delivery. Retrospective studies suggest that induction of labor in pregnant women with cholestasis gives similar obstetric results to conservative treatment in a population of healthy pregnant women. A lower number of stillbirths have also been found in cases of induction at 37 weeks compared to historical controls [45]. A retrospective analysis of a cohort of pregnant women with and without cholestasis indicates that delivery at 36 weeks reduces the risk of intrauterine fetal demise and compensates for the risk of neonatal complications [46]. Given the lack of randomized trial-based recommendations for optimal management of ICP, most experts suggest inducing labor between 36 and 37 weeks of pregnancy, especially if the concentration of bile acids exceeds $40 \mathrm{mmol} / \mathrm{L}$ [47].

\section{Recommendation}

Labor induction in pregnancies complicated by ICP is recommended due to a risk of fetal complications if the concentrations of bile acids are:

- $\geq 100 \mathrm{mmol} / \mathrm{L}$ after 34 weeks of gestation;

- 40-99 $\mathrm{mmol} / \mathrm{L}$ after 36 weeks of gestation;

- 10-39 $\mathrm{mmol} / \mathrm{L}$ after 38 weeks of gestation.

\section{Labor induction in pregnant women of advanced reproductive age}

The risk of pregnancy complications, including unexplained stillbirth and maternal mortality, increases in women of advanced reproductive age [48]. The mechanism responsible for the increased risk of intrauterine fetal death without structural defects in older women has not been explained so far. A meta-analysis of randomized trials has shown that induction of labor in women over 35 years of age is not associated with an increased risk of maternal or fetal complications and caesarean section $[49,50]$. Due to the risk of stillbirth in pregnant women of advanced reproductive age, it is recommended to treat pregnancies of women aged 40 and more as biologically mature at 39 weeks and consider the possibility of labor induction.

\section{Recommendation}

Labor induction in pregnant women over the age of 40 is recommended after 39 weeks of gestation due to an increased risk of intrauterine fetal death.

\section{INDUCTION OF LABOR - CONDITIONS AND METHODS}

\section{The maturity of the cervix}

The morphological and functional maturity of the cervix determines successful labor induction. The first scoring system allowing for the assessment of cervical maturity was the Bishop score described in 1964 [51]. It is assumed that the cervix is prepared for the induction of labor at a score of at least 6 (Tab. 4).

A meta-analysis of studies comparing the Bishop score and transvaginal sonography in the evaluation of the maturity of the cervix before labor induction has shown that neither of these methods is more effective in determining clinically relevant endpoints including the date of labor induction [52]. Therefore, the Bishop score remains the most commonly recommended method for assessing the maturity of the cervix.

\section{Pre-induction of labor in unripe cervix}

The current methods of labor pre-induction include pharmacological (prostaglandin $E_{2}$ - dinoprostone and prostaglandin $\mathrm{E}_{1}$ - misoprostol) and mechanical methods (membrane stripping, artificial rupture of membranes, a Foley catheter and a double-balloon catheter).

\section{The use of mechanical methods for labor pre-induction}

The mechanical methods involve direct dilation of the cervix and the lower uterine segment (Tab. 5).

The use of a Foley catheter for labor pre-induction

A urinary Foley catheter is among the most common non-pharmacological methods used for labor pre-induction. Its application was first described in 1863. Cervical ripening with a Foley catheter involves direct dilation of the cervix and the lower uterine segment using a saline-filled balloon, as well as membrane stripping to increase local prostaglandin release. 
Table 2. Summary of recommendations

\section{Summary of recommendations}

1. The decision to induce labor should always be justified on medical grounds and preceded by obtaining a written informed consent from the pregnant woman. (Level D)

2. Labor induction is recommended in well-dated pregnancies (taking account of fetal biometry between 8 and 14 weeks of gestation) at 41 weeks to 41 weeks +6 days, regardless of the state of the cervix, taking account of the fact that interventions at this time reduce perinatal mortality without increasing perinatal morbidity or the percentage of caesarean sections. (Level A)

3. Labor induction is not recommended in pregnant women with PPROM before 34 weeks of gestation in the absence of symptoms of intrauterine infection due to a high risk of complications associated with pre-term birth. Expectant management using a steroid therapy and antibiotic prophylaxis is recommended. (Level A)

4. Labor induction is not recommended in pregnant women with PPROM between 34 and 37 weeks of gestation in the absence of symptoms of intrauterine infection because it does not reduce the risk of complications of neonatal sepsis and may be associated with a higher risk of respiratory complications in newborns. Expectant management with prophylactic antibiotics is recommended. (Level A)

5. Delivery in women with PPROM is recommended in cases of intrauterine infection, regardless the gestational age. Labor approach need to be adequate to clinical conditions. (Level D)

6. Labor induction is recommended in pregnant women with PPROM after 37 weeks of gestation due to a reduced risk of maternal and neonatal complications. (Level A)

7. Labor induction in pregnancies with suspected LGA fetuses can be considered after 39 weeks, as it may reduce the risk of shoulder dystocia and caesarean section, but a relatively high risk of error in the ultrasound estimation of the fetal weight must be taken into account. (Level A)

8. Labor induction at the estimated fetal weight exceeded $4.500 \mathrm{~g}$ is not recommended due to a high risk of shoulder dystocia. (Level C)

9. Labor induction in women with IUGR is not recommended before 34 weeks of gestation due to a high risk of complications associated with pre-term delivery. (Level A)

10. Labor induction in women with IUGR is not recommended between 34 and 36 weeks due to a risk of complications associated with late preterm delivery. (Level A)

11. Labor induction in women with suspected IUGR is recommended after 37 weeks due to an increased risk of intrauterine fetal death. (Level C)

12. Labor induction in twin monochorionic diamniotic pregnancy, in the absence of contraindications to vaginal delivery, should be considered between 36 and 37 weeks of gestation due to an increased risk of the intrauterine death of the fetus/fetuses. (Level B)

13. Labor induction in twin dichorionic pregnancy, in the absence of contraindications to vaginal delivery, should be considered between 37 and 38 weeks of gestation due to an increased risk of the intrauterine death of the fetus/fetuses. (Level A)

14. Labor induction in twin monoamniotic pregnancy is contraindicated. (Level D)

15. Labor induction in pregnant women with uncomplicated hypertension should be considered after 38 weeks of gestation due to an increased risk of maternal complications. (Level A)

16. Delivery should be considered in women with hypertension and additional complications, regardless gestational age. Labor approach need to be adequate to clinical conditions. (Level D)

17. Labor induction in women with pregestational diabetes mellitus should be considered after 38 weeks due to an increased risk of fetal complications. (Level C)

18. Labor induction in pregnancy complicated gestational diabetes should be considered after 39 weeks due to an increased risk of fetal complications. (Level C)

19. In case of suspected excessive fetal growth in diabetic pregnancy when the estimated fetal weight exceeds above $4000 \mathrm{~g}$ and/or the difference between AD and BPD above $2.6 \mathrm{~cm}$, the induction of labor is contradicted due to an increased risk of shoulder dystocia. (Level C)

20. Labor induction in pregnancies complicated by ICP is recommended due to a risk of fetal complications if the concentrations of bile acids are (Level C):

$\longrightarrow 100 \mathrm{mmol} / \mathrm{L}$ after 34 weeks of gestation;

$-40-100 \mathrm{mmol} / \mathrm{L}$ after 36 weeks of gestation;

$-10-39 \mathrm{mmol} / \mathrm{L}$ after 38 weeks of gestation.

21. Labor induction in pregnant women over the age of 40 is recommended after 39 weeks of gestation due to an increased risk of intrauterine fetal death. (Level B)

Table 3. Strength of recommendations

\section{Strength of recommendations}

Level A — recommendations are based on evidence obtained from randomized, controlled trials

Level B - recommendations are based on evidence obtained from controlled trials without randomization

Level C - recommendations are based on evidence obtained from cohort or case-control analytic studies and from multiple time series with or without the intervention

Level D — recommendations are based on expert committee reports or opinions or clinical experience of respected authorities 


\begin{tabular}{|l|c|c|c|}
\hline \multirow{2}{*}{ Factor } & \multicolumn{3}{|c|}{ Score } \\
\cline { 2 - 4 } & $\mathbf{0}$ & $\mathbf{1}$ & $\mathbf{2}$ \\
\hline Dilation (cm) & 0 & $1-2$ & $3-4$ \\
\hline Effacement (\%) & $0-30$ & $40-50$ & $60-70$ \\
\hline Consistency & Firm & Medium & Soft \\
\hline Position & Posterior & Midposition & Anterior \\
\hline Station & -3 & -2 & -1 \\
\hline
\end{tabular}

Table 5. Contraindications to mechanical dilation of the cervix

\section{Contraindications to mechanical dilation of the cervix}

Vaginal bleeding

Placenta previa

Premature rupture of membranes - relative contraindication

The use of a Foley catheter for labor pre-induction is a simple and cheap method and it has few side effects compared to pharmacological agents used for cervical ripening [53]. In 2012, the Cochrane Database published a meta-analysis of the effectiveness of mechanical methods in pre-induction of labor. The authors have concluded that the effectiveness of mechanical methods is comparable to that of prostaglandins in inducing labor within 24 hours at a comparable risk of caesarean section and a lower risk of hyperstimulation of the uterus [54].

\section{A double-balloon catheter \\ - Cook cervical ripening balloon}

In 1991, Dr Atad from Israel published the first report on a double-balloon catheter (DBC) designed specifically for labor pre-induction. The current model of this catheter consists of a rigid stylet and two balloons: a uterine balloon which is positioned in the cervical internal os and a cervical-vaginal balloon for positioning at the cervical external os. The mechanism of action is similar to that of a Foley catheter. Studies on the efficiency of DBC have demonstrated that its efficacy for cervical ripening is higher than or comparable with pharmacological methods [55].

\section{The use of prostaglandins for labor pre-induction}

Any obstetric situations requiring vaginal termination of pregnancy in patients with concomitant unripe cervix are indications for the application of prostaglandins [56] (Tab.6).

Nowadays two prostaglandins are accepted for use in pre-induction of labor with a live fetus, as well as in abortion/delivery of a stillbirth fetus and non-viable fetus in Poland. These are PGE2 (dinoprostone - vaginal gel $[0.5 \mathrm{mg} / 3 \mathrm{~g}]$ and a vaginal delivery system [0.005 g/12 h])
Table 6. Contraindications to the use of prostaglandins

\begin{tabular}{l}
\hline Contraindications to the use of prostaglandins \\
Uterine scarring after previous cesarean sections or other operations \\
\hline Feto-pelvic disproportion \\
\hline Previous operative deliveries (with forceps or ventouse) \\
\hline Six or more deliveries in the past \\
\hline Presentation other than the longitudinal cephalic presentation \\
\hline Symptoms of acute health risks to the fetus \\
\hline Rupture of membranes - relative contraindication \\
\hline Allergy to prostaglandins or carrier components \\
Bronchial asthma, glaucoma or elevated intraocular pressure \\
\hline Placenta previa, unexplained vaginal bleeding
\end{tabular}

and PGE1 (misoprostol - a vaginal delivery system comprising $200 \mu \mathrm{g}$ of misoprostol with a release rate of $7 \mu \mathrm{g} / \mathrm{h}$ ).

A meta-analysis has shown that the vaginal delivery of prostaglandins is the most effective method in labor pre-induction compared to other routes of administration [57]. When choosing prostaglandin for labor pre-induction, one should remember that these two molecules differ significantly in terms of pharmacokinetics: misoprostol has a much stronger uterotonic effect than dinoprostone and is therefore more effective in less mature cervix, e.g. in primiparous women.

\section{Induction of labor in mature cervix}

The use of oxytocin for labor induction

The indication for oxytocin use is the need for labor induction in mature cervix. Studies have shown that the highest doses of oxytocin are needed in primiparous women, before the $36^{\text {th }}$ week of pregnancy, at the cervical dilation of less than $2 \mathrm{~cm}$ [58]. The Cochrane Database contains a recently published meta-analysis comparing the efficacy of different doses of oxytocin in labor induction [59]. This comparison has shown no clinically relevant differences with the exception of an increased risk of uterine hyperstimulation associated with higher doses of oxytocin.

Data published in 2004 show that prolonged infusion of oxytocin after reaching an effective uterine contractions 
and the start of the active phase of labor does not bring any clear benefits (cervical dilation $>5 \mathrm{~cm}$ ) [60].

The most serious complication of labor induction with oxytocin is uterine hyperstimulation, which is associated with a risk of prolonged tonic contractions and fetal hypoxia. The greatest risk of uterine rupture occurs in women who had a surgery on the uterus in the past and in multiparous women.

\section{Membrane stripping}

Membrane stripping or membrane sweeping is mechanical separation of membranes from the lower uterine segment to initiate local prostaglandin release and hasten labor. The simultaneous insertion of one or two fingers through the cervical os initiates endogenous oxytocin release and the Ferguson reflex.

This intervention is highly efficient and helps avoid labor induction using conventional pharmacological methods and amniotomy. When used as an adjunct to other labor induction techniques, this method allows for decreasing doses of oxytocin and increasing the percentage of vaginal deliveries [61]. Routine use of this treatment from 38 weeks of pregnancy does not bring any clinically significant benefits. Complications associated with membrane stripping include infection, bleeding and accidental rupture of membranes and are relatively rare.

\section{The use of amniotomy for induction of labor}

Amniotomy is artificial rupture of membranes, which leads to the stimulation of uterine contractility through the release of prostaglandins and oxytocin to accelerate or shorten labor. This procedure was first described in 1756. It is currently one of the most commonly performed procedures in obstetrics [62]. Performing amniotomy at cervical dilation of less than $2 \mathrm{~cm}$ and immature cervix (hard, pointing toward the sacrum) is associated with an increased incidence of labor dystocia, ascending infection and caesarean sections [62]. If the cervix is dilated to 3-4 cm after the spontaneous start of labor, amniotomy can shorten the active phase of dilation by more than a third (Tab. 7, 8).

When making a decision to perform amniotomy, one should consider the risks associated with the procedure, such as umbilical cord prolapse, acute fetal hypoxia, fetal damage, abnormal engagement of the head, as well as the risk of intrauterine infection in the case of prolonged rupture of membranes. Intrauterine infection (if delivery takes longer than 12 hours) can be prevented by antibiotic therapy and less frequent vaginal examinations.

The largest study published to date of the efficacy of amniotomy is labor induction in mature cervix involved

\section{Table 7. Preconditions for amniotomy}

\section{Preconditions for amniotomy}

Careful obstetric interview and evaluation of test results

Engagement of the presenting part of the fetus in the pelvic inlet

Favorable Bishop score assessment of the cervix

Aseptic and antiseptic conditions

\section{Table 8. Contraindications to amniotomy}

\section{Absolute contraindications}

Abnormal fetal presentation: small parts first (including the umbilical cord)

Vasa previa

Vaginosis

Breech presentation

Absolute indications for cesarean section

Relative contraindications

Polyhydramnios

No engagement of the head in the pelvis

Pre-term delivery

Unripe cervix

more than 3.500 patients. The study has shown that this method is useful as a sole method of labor induction [62].

The clinical utility of early amniotomy after the removal of a Foley catheter has also been analyzed. It has been found that the rapture of membranes not later than one hour after removal of the catheter significantly reduces the duration of induction in nulliparous women [63].

Furthermore, the cost-effectiveness of early amniotomy has been compared after the application of vaginal gel containing $\mathrm{PGE}_{2}$ in patients with Bishop score $<7$. It has been found that amniotomy is more cost-effective than a repeated vaginal administration of prostaglandin [64].

\section{Induction of labor in intrauterine fetal death}

Administering misorpostol is the most effective method of inducing labor in intrauterine fetal death at $<28$ weeks of pregnancy, regardless of the outcome of a clinical assessment of cervical maturity [65]. Misoprostol must not be used in third-trimester intrauterine fetal death after caesarean section due to a risk of uterine rupture (1.2-10\%). Using a Foley catheter is a useful method of inducing labor in intrauterine fetal death at $>28$ weeks of pregnancy. If administration of oxytocin is necessary, it can be infused intravenously 4 hours after the last dose of misoprostol. 


\section{REFERENCES}

1. Nicholson JM, Kellar LC, Henning GF, et al. The association between the regular use of preventive labour induction and improved term birth outcomes: findings of a systematic review and meta-analysis. BJOG. 2015; 122(6): 773-784, doi: 10.1111/1471-0528.13301, indexed in Pubmed: 25716067.

2. Whitworth $M$, Bricker L, Neilson JP, et al. Ultrasound for fetal assessment in early pregnancy. Cochrane Database Syst Rev. 2000(2): CD000182, doi: 10.1002/14651858.CD000182, indexed in Pubmed: 10796174.

3. Caughey AB, Nicholson JM, Washington AE. First- vs second-trimester ultrasound: the effect on pregnancy dating and perinatal outcomes. Am J Obstet Gynecol. 2008; 198(6): 703.e1-5; discussion 703.e5, doi: 10.1016/j.ajog.2008.03.034, indexed in Pubmed: 18538160.

4. Blondel B, Morin I, Platt RW, et al. Algorithms for combining menstrual and ultrasound estimates of gestational age: consequences for rates of preterm and postterm birth. BJOG. 2002; 109(6): 718-720, indexed in Pubmed: 12118654.

5. Gulmezoglu AM, Crowther CA, Middleton $P$, et al. Induction of labour for improving birth outcomes for women at or beyond term. Cochrane Database Syst Rev 2012;6:CD00. 4945.

6. Rozporządzenie Ministra Zdrowia z dnia 20 września 2012 r. w sprawie standardów postępowania medycznego przy udzielaniu świadczeń zdrowotnych z zakresu opieki okołoporodowej sprawowanej nad kobietą w okresie fizjologicznej ciąży, fizjologicznego porodu, połogu oraz opieki nad noworodkiem. Dz U. ; 12: 1100.

7. Rozporządzenie Ministra Zdrowia z dnia 9 listopada 2015 r.w sprawie standardów postępowania medycznego przy udzielaniu świadczeń zdrowotnych w dziedzinie położnictwa i ginekologii z zakresu okołoporodowej opieki położniczo-ginekologicznej, sprawowanej nad kobietą w okresie ciąży, porodu, połogu, w przypadkach występowania określonych powikłań oraz opieki nad kobietą w sytuacji niepowodzeń położniczych. Dz.U. 2015, poz. ; 2007.

8. Buchanan SL. CrowtherCA, LevettKM, Middleton P, Morris J. Planned early birth versus expectantmanagement for women with preterm prelabour rupture of membranes prior to 37 weeks' gestation for improving pregnancy outcome. Cochrane Database of Systematic Reviews 2010, Issue 3. Art. No. : CD00. 4735.

9. van der Ham DP, van der Heyden JL, Opmeer BC, et al. Management of late-preterm premature rupture of membranes: the PPROMEXIL-2 trial. Am J Obstet Gynecol. 2012; 207(4): 276.e1-276.10, doi: 10.1016/j. ajog.2012.07.024, indexed in Pubmed: 22901981.

10. Morris JM1, Roberts CL2, Bowen JR3, Patterson JA2, Bond DM2, Algert CS2, Thornton JG4, Crowther CA5; PPROMT Collaboration. Immediate delivery compared with expectant management after preterm pre-labour rupture of the membranes close to term (PPROMT trial): a randomised controlled trial. Lancet. 2016 Jan 30. ; 387(10017): 444-52.

11. Roberts D, Dalziel S. Antenatal corticosteroids for accelerating fetal lung maturation for women at risk of preterm birth. Cochrane Database Syst Rev. 2006(3): CD004454, doi: 10.1002/14651858.CD004454.pub2, indexed in Pubmed: 16856047.

12. Lee MJ, Davies J, Guinn D, et al. Single versus weekly courses of antenatal corticosteroids in preterm premature rupture of membranes. Obstet Gynecol. 2004; 103(2): 274-281, doi: 10.1097/01. AOG.0000110249.84858.90, indexed in Pubmed: 14754695.

13. Kenyon S, Boulvain M, Neilson JP. Antibiotics for preterm rupture of membranes. Cochrane Database Syst Rev. 2013(12): CD001058, doi: 10.1002/14651858.CD001058.pub3, indexed in Pubmed: 24297389.

14. Hannah ME, Ohlsson A, Farine D, et al. Induction of labor compared with expectant management for prelabor rupture of the membranes at term. TERMPROM Study Group. N Engl J Med. 1996; 334(16): 1005-1010, doi: 10.1056/NEJM199604183341601, indexed in Pubmed: 8598837.

15. Middleton P, Shepherd E, Flenady V, et al. Planned early birth versus expectant management (waiting) for prelabour rupture of membranes at term (37 weeks or more). Cochrane Database Syst Rev. 2017; 1: CD005302, doi: 10.1002/14651858.CD005302.pub3, indexed in Pubmed: 28050900.

16. Di Renzo GC, Melin P, Berardi A, et al. Intrapartum GBS screening and antibiotic prophylaxis: a European consensus conference. J Matern Fetal Neonatal Med. 2015; 28(7): 766-782, doi: 10.3109/14767058.2014.9348 04, indexed in Pubmed: 25162923.

17. Ju $\mathrm{H}, \mathrm{Chadha} Y$, Donovan $\mathrm{T}$, et al. Fetal macrosomia and pregnancy outcomes. Aust N Z J Obstet Gynaecol. 2009; 49(5): 504-509, doi: 10.1111/j.1479-828X.2009.01052.x, indexed in Pubmed: 19780734.

18. Das S, Irigoyen M, Patterson MB, et al. Neonatal outcomes of macrosomic births in diabetic and non-diabetic women. Arch Dis Child Fetal Neonatal
Ed. 2009; 94(6): F419-F422, doi: 10.1136/adc.2008.156026, indexed in Pubmed: 19531522.

19. Drooger JC, Troe JWM, Borsboom GJ, et al. Ethnic differences in prenatal growth and the association with maternal and fetal characteristics. UItrasound Obstet Gynecol. 2005; 26(2): 115-122, doi: 10.1002/uog.1962, indexed in Pubmed: 16038011.

20. Vora N, Bianchi DW. Genetic considerations in the prenatal diagnosis of overgrowth syndromes. Prenat Diagn. 2009; 29(10): 923-929, doi: 10.1002/pd.2319, indexed in Pubmed: 19609940.

21. Pinette MG, Pan Y, Pinette SG, et al. Estimation of fetal weight: mean value from multiple formulas. J Ultrasound Med. 1999; 18(12): 813-817, indexed in Pubmed: 10591444.

22. Coomarasamy A, Connock M, Thornton J, et al. Accuracy of ultrasound biometry in the prediction of macrosomia: a systematic quantitative review. BJOG. 2005; 112(11): 1461-1466, doi: 10.1111/j.1471-0528.2005.00702.x, indexed in Pubmed: 16225563.

23. Boulvain M, Senat MV, Perrotin F, et al. Induction of labour versus expectant management for large-for-date fetuses: a randomised controlled trial. The Lancet. 2015; 385(9987): 2600-2605, doi: 10.1016/s01406736(14)61904-8.

24. Boulvain M, Irion O, Dowswell T, et al. Induction of labour at or near term for suspected fetal macrosomia. Cochrane Database of Systematic Reviews. 2016, doi: 10.1002/14651858.cd000938.pub2.

25. NesbittTS, GilbertWM, Herrchen B. Shoulder dystocia and associated risk factors with macrosomic infants born in California. Am J Obstet Gynecol. 1998; 179(2): 476-480, indexed in Pubmed: 9731856.

26. Turan S, Miller J, Baschat AA. Integrated testing and management in fetal growth restriction. Semin Perinatol. 2008; 32(3): 194-200, doi: 10.1053/j. semperi.2008.02.008, indexed in Pubmed: 18482621.

27. Lees C, Marlow N, Arabin B, et al.TRUFFLE Group. Perinatal morbidity and mortality in early-onset fetal growth restriction: cohort outcomes of the trial of randomized umbilical and fetal flow in Europe (TRUFFLE). Ultrasound Obstet Gynecol. 2013; 42(4): 400-408, doi: 10.1002/uog.13190, indexed in Pubmed: 24078432.

28. Figueras F, Gratacós E. Update on the diagnosis and classification of fetal growth restriction and proposal of a stage-based management protocol. Fetal Diagn Ther. 2014; 36(2): 86-98, doi: 10.1159/000357592, indexed in Pubmed: 24457811.

29. Joseph KS, Liu S, Demissie K, et al. The Fetal and Infant Health Study Group of the Canadian Perinatal Surveillance System. A parsimonious explanation for intersecting perinatal mortality curves: understanding the effect of plurality and of parity. BMC Pregnancy Childbirth. 2003; 3(1): 3, doi: 10.1186/1471-2393-3-3, indexed in Pubmed: 12780942.

30. Burgess JL, Unal ER, Nietert PJ, et al. Risk of late-preterm stillbirth and neonatal morbidity for monochorionic and dichorionic twins. Am J Obstet Gynecol. 2014; 210(6): 578.e1-578.e9, doi: 10.1016/j. ajog.2014.03.003, indexed in Pubmed: 24607757.

31. Hack KEA, Derks JB, Elias SG, et al. Perinatal mortality and mode of delivery in monochorionic diamniotic twin pregnancies $\geq 32$ weeks of gestation: a multicentre retrospective cohort study. BJOG. 2011;118(9): 1090-1097, doi: 10.1111/j.1471-0528.2011.02955.x, indexed in Pubmed: 21585638.

32. Rossi AC, Prefumo F. Impact of cord entanglement on perinatal outcome of monoamniotic twins: a systematic review of the literature. Ultrasound Obstet Gynecol. 2013;41(2): 131-135, doi: 10.1002/uog.12345, indexed in Pubmed: 23371346.

33. Vilchez GA, Dai J, Hoyos LR, et al. Optimal timing for term delivery of twin pregnancies: a population-based study. Am J Perinatol. 2015; 32(5): 487-496, doi: 10.1055/s-0034-1396693, indexed in Pubmed: 25545449.

34. Wood S, Tang S, Ross S, et al. Stillbirth in twins, exploring the optimal gestational age for delivery: a retrospective cohort study. BJOG. 2014; 121(10): 1284-90; discussion 1291, doi: 10.1111/1471-0528.12866, indexed in Pubmed: 24888505.

35. Dodd JM, Crowther CA, Haslam RR, et al. Twins Timing of Birth Trial Group. Elective birth at 37 weeks of gestation versus standard care for women with an uncomplicated twin pregnancy at term: the Twins Timing of Birth Randomised Trial. BJOG. 2012; 119(8): 964-973, doi: 10.1111/j.1471-0528.2012.03356.x, indexed in Pubmed: 22691051.

36. Hoffmann E, Oldenburg A, Rode L, et al. Twin births: cesarean section or vaginal delivery? Acta Obstet Gynecol Scand. 2012; 91(4): 463-469, doi: 10.1111/j.1600-0412.2011.01356.x, indexed in Pubmed: 22432546.

37. Barrett JFR, Hannah ME, Hutton EK, et al. Twin Birth Study Collaborative Group. A randomized trial of planned cesarean or vaginal delivery for twin pregnancy. N Engl J Med. 2013; 369(14): 1295-1305, doi: 10.1056/NEJMoa1214939, indexed in Pubmed: 24088091. 
38. Hutcheon JA, Lisonkova S, Magee LA, et al. Optimal timing of delivery in pregnancies with pre-existing hypertension. BJOG. 2011; 118(1): 49-54, doi: 10.1111/j.1471-0528.2010.02754.x, indexed in Pubmed: 21054760.

39. Koopmans CM, Bijlenga D, Groen H, et al. HYPITAT study group. Induction of labour versus expectant monitoring for gestational hypertension or mild pre-eclampsia after 36 weeks' gestation (HYPITAT): a multicentre, open-label randomised controlled trial. Lancet. 2009; 374(9694): 979-988, doi: 10.1016/S0140-6736(09)60736-4, indexed in Pubmed: 19656558.

40. Burkhardt T, Schmidt M, Kurmanavicius J, et al. Evaluation of fetal anthropometric measures to predict the risk for shoulder dystocia. Ultrasound Obstet Gynecol. 2014;43(1): 77-82, doi: 10.1002/uog.12560, indexed in Pubmed: 23836579.

41. Kjos SL, Henry OA, Montoro M, et al. Insulin-requiring diabetes in pregnancy: a randomized trial of active induction of labor and expectant management. Am J Obstet Gynecol. 1993; 169(3): 611-615, indexed in Pubmed: 8372870

42. Sutton AL, Mele L, Landon MB, et al. Eunice Kennedy Shriver National Institute of Child Health and Human Development Maternal-Fetal Medicine Units Network. Delivery timing and cesarean delivery risk in women with mild gestational diabetes mellitus. Am J Obstet Gynecol. 2014; 211(3): 244.e1-244.e7, doi: 10.1016/j.ajog.2014.03.005, indexed in Pubmed: 24607755.

43. Melamed N, Ray JG, Geary M, et al. Induction of labor before 40 weeks is associated with lower rate of cesarean delivery in women with gestational diabetes mellitus. Am J Obstet Gynecol. 2016; 214(3): 364.e1-364. e8, doi: 10.1016/j.ajog.2015.12.021, indexed in Pubmed: 26928149.

44. Kawakita T, Parikh L, Ramsey $P$, et al. Predictors of adverse neonatal outcomes in intrahepatic cholestasis of pregnancy. Am J Obstet Gynecol. 2015; 213(4): 570.e1-570.e8, doi: 10.1016/j.ajog.2015.06.021.

45. Puljic A, Kim E, Page J, et al. The risk of infant and fetal death by each additional week of expectant management in intrahepatic cholestasis of pregnancy by gestational age. Am J Obstet Gynecol. 2015; 212(5):667.e1667.e5, doi: 10.1016/j.ajog.2015.02.012, indexed in Pubmed: 25687562

46. Lo JO, Shaffer BL, Allen AJ, et al. Intrahepatic cholestasis of pregnancy and timing of delivery. J Matern Fetal Neonatal Med. 2015; 28(18): 2254-2258, doi: 10.3109/14767058.2014.984605, indexed in Pubmed: 25371372.

47. Friberg AK, Zingmark V, Lyndrup J. Early induction of labor in high-risk intrahepatic cholestasis of pregnancy: what are the costs? Arch Gynecol Obstet. 2016; 294(4): 709-714, doi: 10.1007/s00404-016-4019-8, indexed in Pubmed: 26825731.

48. Walker KF, Bugg G, Macpherson M, et al. Induction of labour versus expectant management for nulliparous women over 35 years of age: a multi-centre prospective, randomised controlled trial. BMC Pregnancy Childbirth. 2012; 12: 145, doi: 10.1186/1471-2393-12-145, indexed in Pubmed: 23231750.

49. Walker KF, Bugg GJ, Macpherson M, et al. 35/39 Trial Group. Randomized Trial of Labor Induction in Women 35 Years of Age or Older. N Engl J Med. 2016; 374(9): 813-822, doi: 10.1056/NEJMoa1509117, indexed in Pubmed: 26962902

50. Walker KF, Malin G, Wilson $\mathrm{P}$, et al. Induction of labour versus expectant management at term by subgroups of maternal age: an individual pa- tient data meta-analysis. Eur J Obstet Gynecol Reprod Biol. 2016; 197: 1-5, doi: 10.1016/j.ejogrb.2015.11.004, indexed in Pubmed: 26686589.

51. Bishop EH. Pelvic scoring for elective induction. Obstet Gynecol. 1964; 24: 266-8, indexed in Pubmed: 14199536.

52. Ezebialu IU, Eke AC, Eleje GU, et al. Methods for assessing pre-induction cervical ripening. Cochrane Database Syst Rev. 2015(6): CD010762, doi: 10.1002/14651858.CD010762.pub2, indexed in Pubmed: 26068943.

53. Alfirevic Z, Keeney E, Dowswell T, et al. Which method is best for the induction of labour? A systematic review, network meta-analysis and cost-effectiveness analysis. Health Technol Assess. 2016; 20(65): 1-584, doi: 10.3310/hta20650, indexed in Pubmed: 27587290.

54. Jozwiak M, Bloemenkamp KWM, Kelly AJ, et al. Mechanical methods for induction of labour. Cochrane Database Syst Rev. 2012(3): CD001233, doi: 10.1002/14651858.CD001233.pub2, indexed in Pubmed: 22419277.

55. Du C, Liu Y, Liu Y, et al. Double-balloon catheter vs. dinoprostone vaginal insert for induction of labor with an unfavorable cervix. Arch Gynecol Obstet. 2015; 291(6): 1221-1227, doi: 10.1007/s00404-014-3547-3, indexed in Pubmed: 25408273.

56. Boulvain M, Kelly A, Irion O. Intracervical prostaglandins for induction of labour. Cochrane Database Syst Rev. 2008(1): CD006971, doi: 10.1002/14651858.CD006971, indexed in Pubmed: 18254122.

57. Thomas J, Fairclough A, Kavanagh J, et al. Vaginal prostaglandin (PGE2 and PGF2a) for induction of labour at term. Cochrane Database Syst Rev. 2014 Jun 19. ; 6: CD003101.

58. Alfirevic Z, Kelly AJ, Dowswell T. Intravenous oxytocin alone for cervical ripening and induction of labour. Cochrane Database Syst Rev. 2009(4): CD003246, doi: 10.1002/14651858.CD003246.pub2, indexed in Pubmed: 19821304.

59. Budden A, Chen LJY, Henry A. High-dose versus low-dose oxytocin infusion regimens for induction of labour at term. Cochrane Database Syst Rev. 2014(10): CD009701, doi: 10.1002/14651858.CD009701.pub2, indexed in Pubmed: 25300173.

60. Daniel-Spiegel E, Weiner Z, Ben-Shlomo I, et al. For how long should oxytocin be continued during induction of labour? BJOG. 2004; 111(4): 331-334, indexed in Pubmed: 15008768.

61. Boulvain $\mathrm{M}, \mathrm{S} \tan \mathrm{C}$, Irion O. Membrane sweeping for induction of labour Cochrane Database Syst Rev. 2005 Jan 25. ; 1: CD000451.

62. Bricker $L$, Luckas M. Amniotomy alone for induction of labour. Cochrane Database Syst Rev. 2000(4): CD002862, doi: 10.1002/14651858. CD002862, indexed in Pubmed: 11034776.

63. Battarbee AN, Palatnik A, Peress DA, et al. Association of Early Amniotomy After Foley Balloon Catheter Ripening and Duration of Nulliparous Labor Induction. Obstet Gynecol. 2016; 128(3): 592-597, doi: 10.1097/AOG.0000000000001563, indexed in Pubmed: 27500341.

64. Beckmann M, Merollini K, Kumar S, et al. Induction of labor using prostaglandin vaginal gel: cost analysis comparing early amniotomy with repeat prostaglandin gel. Eur J Obstet Gynecol Reprod Biol. 2016; 199: 96-101, doi: 10.1016/j.ejogrb.2016.01.041, indexed in Pubmed: 26914400.

65. WHO recommendations for induction of labour 2011. http://www. who.int/reproductivehealth/publications/maternal_perinatal_health/9789241501156/en/ 